\title{
VITAMIN D LEVELS IN MULTIPLE SCLEROSIS
}

\author{
Zeynep Hülya Durmaz ${ }^{1}$, Elif Menekşe ${ }^{1}$, Durmuş Ayan ${ }^{2}$, Aslıhan Dilara Demir ${ }^{3}$, Hatice Dörtok Demir ${ }^{1}$, Ayşe Akyüz ${ }^{4}$ \\ Correspondence: aakdenizhulyaa2141@gmail.com \\ ${ }^{I}$ Department of Biochemistry, Amasya Üniversitesi Sabuncuoğlu Şerefeddin Ĕ̆itim ve Araştırma Hastanesi, Turkey \\ ${ }^{2}$ Department of Biochemistry, Amasya Central Public Health Laboratory Amasya, Turkey Amasya Turkey \\ ${ }^{3}$ Department of Internal Medicine Amasya Üniversitesi Sabuncuoğlu Şerefeddin Eğitim ve Araştırma Hastanesi, Turkey \\ ${ }^{4}$ Department of Neurology Amasya Üniversitesi Sabuncuoğlu Şerefeddin Eğitim ve Araştırma Hastanesi, Turkey
}

\section{Article History:}

Received: July 10, 2019

Accepted: December 20, 2019

Published: January 1, 2020

\section{Cite this as:}

Durmaz ZH, Menekse E, Ayan D, Demir AD, Demir HD, Akyuz A.

Vitamin d levels in multiple sclerosis. Malang Neurology Journal;

2020.6:28-31.

http://dx.doi.org/10.21776/ub.mnj.202 0.006.01.6

\section{ABSTRACT}

Background: Multiple Sclerosis is a neurologic disease that effect Central Nervous System(CNS). Vitamin D is a liposoluble prohormone. İt is thought that vitamin D deficiency is responsible for Lots of diseases which includes MS . In this study, we aimed to show the relationship between serum vitamin D level and MS

Objective: In our research we wanted to show the serum vitamin D levels in MS patients.

Methods: We included 106 patients (76 female, 30 male) to our study. Participants were divided into two groups as patient and control group. Serum vitamin D levels were evaluated.

We excluded patients with known liver or renal disease. Liver enzymes and blood creatinine of the patients included in the study were normal.

Results: There was a statistically significant difference when comparing two groups of serum vitamin D results. Serum vitamin D levels were lower in the control group. No correlation was found between vitamin $\mathrm{D}$ and age. There was no correlation between vitamin $\mathrm{D}$ and gender. According to the vitamin D level reference interval in the MS group, 28 patients had deficiency, 17 patients had failure, and 12 patients were normal. In the control group, according to the vitamin D level reference range, 35 patients had deficiency, 11 patients had failure and 3 patients were normal.

Conclusion: In this study conducted with limited facilities, lower vitamin D levels in the control group suggested that vitamin D levels may be low when the population is examined in general. Vitamin D support throughout the population may reduce the prevalence of other diseases thought to be caused by vitamin D deficiency as well as MS.

Keywords: Multiple sclerosis, vitamin D, autoimmune

\section{Introduction}

Multiple Sclerosis (MS) is a chronic disease that occurs in the white matter in Central nervous system (CNS) and in the areas of inflammation, demyelination and glial sclerosis. It is an autoimmune disease. Oligodendroglia, mediated by $\mathrm{T}$ cells and cytokines are responsible from pathogenesis. There are many intensive researches on its pathogenesis and treatment. ${ }^{1}$ it's etiology is not known exactly. Autoimmune and infectious mechanisms are charged. ${ }^{2}$ Vitamin D is a steroid prohormone. It is taken by digestion with food or is synthesized from 7-dehydrocholesterol in the subcutaneous fat tissue by the effect of the sun's ultraviolet light. It is a fatsoluble vitamin3. It's low levels are thought to cause an increase of being MS in individuals. ${ }^{4}$ In a study, Nikanfar M and friends showed that MS patients had vitamin D deficiency. However, they said no correlation between vitamin D levels and disability. ${ }^{5}$ We aimed to study serum vitamin D levels in MS patients whom apply for rutin neurology policlinic control.

\section{Methods}

MS patients who applied to the neurology outpatient department of our hospital between 01.01.2018 - 01.12.2018 were included in the study with the patient database of
Amasya University Sabuncuoğlu Şerefeddin Training and Research Hospital. 106 MS patients (76 female, 30 male) participated to the study. We diagnosed it according to MRI findings.

The initial values of the patients in the hospital were evaluated. Patients with known liver and renal function were excluded from the study. Liver enzymes and blood creatinine of the patients included in the study were normal. Serum vitamin D measurements (normal values: 25-80 temg / L) were studied with the electrochemiluminescence method in Roche cobas 8000 device. The ethics comittee approval was taken from Amasya University Research Hospital Ethics Comittee at 11.02.2019 with the number of 62949364/929E1149.

SPSS 15 for Windows program was used for data statistics. Descriptive statistics were given as median, interquartile range (IQR) and percentage (\%). Normal distribution skewness and kurtosis values were determined by Kolmogorov-Smirnov (Lillie fors Significance Correction), Shapiro-Wilk tests and distribution of histogram graphs. While the independent two group comparisons which did not meet the normal distribution condition for the numerical variables were determined by the "Mann Whitney U" test, Spearman Correlation Analysis which is nonparemetric 
analysis was performed for correlation. Alpha significance level was accepted as $\mathrm{p}<0.05$.

\section{Results}

Table 1. Vitamin D levels according to groups

\begin{tabular}{cccc}
\hline & MS Vitamin D & Control Vitamin D & P value \\
\hline Median & $20,8(12,2-$ & $14,8(9,1-23,1)$ & $0,002^{* *}$ \\
$(\mathrm{IQR})$ & $27,9)$ & &
\end{tabular}

Alpha significance level $p<0,05$, IQR: interquartilerange

There was a statistically significant difference when comparing two groups of serum vitamin D results.

Table 2: Average age of groups

\begin{tabular}{ccccc}
\hline & \multicolumn{2}{c}{ MS $(\mathrm{n}=57)$} & \multicolumn{2}{c}{ Control $(\mathrm{n}=49)$} \\
\hline Age & \multicolumn{2}{c}{$40(35,5-45,5)$} & \multicolumn{2}{c}{$24(20-33,5)$} \\
Gender & Female & Male & Female & Male \\
& $40(70,2)$ & $17(29,8)$ & $36(\% 73,5)$ & $13(\% 26,5)$ \\
\end{tabular}

\section{Spearman Correlation results:}

For MS; No correlation was found between vitamin D and age and also vitamin D and gender. According to the vitamin $\mathrm{D}$ reference range in the MS group: Deficiency in 28 patients (49.1\%) (9 males (32.2\%), 19 females $(67.8 \%)$, failure in 17 patients $(29.8 \%)$ (6 males $(32.3 \%), 11$ females $(64.7 \%), 12$ patients were normal $(21.1 \%)$ (2 men $(16.7 \%)$, 10 women (83.3\%). According to the vitamin D reference range in the control group:, Deficiency in 35 patients $(71.4 \%)$ (6 men $(17.2 \%), 29$ women $(82.8 \%)$, failure in 11 patients $(22,4 \%)(5$ males $(45,5 \%), 6$ females $(54,5 \%)$.

\section{Discussion}

MS has an unknown etiology. In the pathogenesis of MS, autoimmune and environmental factors may be responsible. Also genetic situation may affect. In recent years, researchers showed that low with D levels are independent risk for MS. Hypovitaminosis D is defined as a low serum vitamin D level that is less than $30 \mathrm{ng} / \mathrm{ml}$. In many studies, the formation, course and activity of MS are thought to be the relationship between sunlight and dietary vitamin D concentration. There are also results from research on the effectiveness of vitamin $\mathrm{D}$ supplementation. It is thought that vitamin $\mathrm{D}$ should be used at higher doses. Most authors think that $4000 \mathrm{IU}$ of preventive vitamin D per day is safe and well tolerated by people living in low latitudes. Vitamin D support is showed to be effective only in cases of actual deficiency. The low cost of vitamin D supplementation is considered to be necessary to reduce the incidence of disease and alleviate the symptoms of multiple sclerosis. ${ }^{6}$

In MS, a reaction develops against myelin in T lymphocytes. This leads to damage to the myelin clip by activating microglia and macrophages. The resulting damage is thought to cause disturbances in the neural conduction. ${ }^{7} 1,25(\mathrm{OH})$ vitamin D stimulates and modulates innate immunity. It plays a role in adaptive immunity and possibly in defense against infection. ${ }^{8}$ Vitamin D is very important for nervous system health and maintanince.
Some animal experiments are very useful for understanding about brain health and related ilness. Animal model data help us strong evidence that vitamin D plays a very important role in proliferation, differentiation, neurotrophism, neuroprotection, and neuroplasticity. In addition to biological function of Vitamin D, it affects gene expression. ${ }^{9}$

In experimental autoimmune encephalomyelitis (EAE) vitamin D was investigated as a treatment of demyelinating disease. While vitamin D alone remained ineffective, calcitriol / vitamin D temporarily increased CNS Helios (+) FoxP3 (+) T cells, and EAE was found to reduce CNS T cells, pathology and neurological deficits in a sustained manner. ${ }^{10} \mathrm{Ms}$ is seen more frequent in areas where vitamin D environmental intake is the lowest. The active hormonal form of vitamin regulates immun system and it has an antiinflammatory effect. In MS vitamin D effects cells expressing enzyme 1 alpha-OHase in the peripheral tissues involved in immunity and neural function. Application of active metabolite 1.25 hydroxy vitamin D by implementing EAE, an animal model of MS in mice and rats prevented disease and reduced disease activity. Vitamin D regulates the dendritic cell, T cell function, macrophages in EAE. Vitamin $\mathrm{D}$ is also works on CNS component cells. Lack of vitamin D, inadequate daylight exposure or low dietary vitamin $\mathrm{D}$ intake, subtle defects in vitamin D metabolism, including vitamin Drelated genetic polymorphisms, may also include. Enough levels of serum vitamin D for a year may prevent patients fromn muscle weakness, bone resorption and fractures. ${ }^{11}$ In EAE, calcitriol and vitamin D3 were investigated in the treatment of a demyelinating disease. There is proof that calcitriol-D vitamin receptor deficiencies may support MS. ${ }^{12}$

It is thought that insufficiency of vitamin D gives rise to MS, frequent relapse, and rapid disease progression. ${ }^{13}$ High vitamin $\mathrm{D}$ levels are thought to be inverse relavent with the chance of multiple sclerosis. Children with vitamin D supplementation is reduced the risk of MS when they are adults. ${ }^{14}$ High dose vitamin D supplementation was thought that immunomodulator might be effective in multiple sclerosis. ${ }^{15}$ In a study conducted on 469 people, magnetic resorance imaging (MRI) and blood values of patients were observed for 5 years. Annual serum vitamin D levels, MRI findings in assosiciation of MS plak on brain, clinical relapse, and morbidity were evaluated. When Vitamin D levels were higher, MS activity is decreased in brain. ${ }^{16}$ There is a relationship between decreased vitamin D level and MS. According to Mendelian randomization study, Genetically reduced vitamin D levels are thought to be strongly associated with increased sensitivity to $\mathrm{MS} .{ }^{17}$ In another research, 136 patients with MS, vitamin D levels were insufficient in MS cases. ${ }^{18}$ In a study evaluating $31 \mathrm{MS}$ patients and 31 healthy siblings, serum vitamin D levels were significantly lower in MS patients compared to healthy siblings. ${ }^{19}$ Soilu-Hanninen $\mathrm{M}$ and friends analyse MRI scans in 66 patients with MS. Combine interferon $\beta-1 b$ and vitamin $\mathrm{D}$ treatment decreases the activity of MS in MRI. ${ }^{20}$

Derakhshandi $\mathrm{H}$ and friends showed that vitamin $\mathrm{D}$ supplementation decreases plaques. $^{21}$ Clinical MS parameters were determined on serum sampling date.

Vitamin D levels were associated with both relapse and morbidity. ${ }^{22,23}$ In another study with vitamin D supplementation the disease progression and activity were not affected, but the number of lesions was found to 
decrease. Acute optic neuritis (AON) was examined whether it is predictive in evaluating the risk of rellaps-remitting multiple sclerosis (RRMS) in patients and whether it is associated with visceral events during the $\mathrm{ON}$ acute phase. AON vitamin D deficiency was high. But not to determine its seriousness. Vitamin D support was not predictive in AON and MS. ${ }^{25}$ Darwish $\mathrm{H}$. and friends also gived vitamin D support to patients, and ultimately it was found that it could improve cognitive performance. ${ }^{26}$ In RRMS patients, Vitamin D supporting reduced the relapses. ${ }^{27}$ Ascherio A and friends suggest that, higher vitamin D levels, declines MS activity and reduces progression incidence were observed. ${ }^{28}$

\section{Conclusion}

In our study, there was a statistically significant difference between two groups of serum vitamin D results. Serum vitamin $\mathrm{D}$ levels were lower in the control group. No correlation was found between vitamin $\mathrm{D}$ and age. There was no correlation between vitamin D and gender. According to the vitamin D reference range in MS group: 28 patients had deficiency, 17 patients had failure and 12 patients were normal. According to the vitamin D reference range in the control group: 35 patients had deficiency, 11 patients had failure and 3 patients were normal.

When we compared the control group and the MS group, the serum vitamin $D$ values were observed to be lower in the control patients. This suggests that vitamin D levels may be low when we look at the general population. We think that reasons such as life style (veiling dressing, inadequate sunlight exposure, etc.), lack of nutrition, season, lack of adequate vitamin D support are some important reasons.

Our study had many limitations. In both groups, lifestyles (veiling dressing, inadequate sunlight exposure, etc.) and feeding habits are not known. At the same time, we saw that vitamin D levels were quite low in healthy individuals too. This claims that vitamin D levels may be low when we look at the general population. Vitamin D support throughout the population may reduce the prevalence of other diseases thought to be caused by vitamin D deficiency just like MS.

Because of the fact that MS disease causes disability in later stages, life style and feeding patterns of individuals may change. This may lead to increased vitamin D deficiency in MS patients. For this reason, vitamin D levels should be observed in routine control of MS patients and vitamin D supplementation may be considered if necessary. However, another important issue here is whether vitamin D deficiency contributes to the emergence of the disease or whether vitamin D levels decrease as a result of the disease. In order to clarify this issue, it can be said that more comprehensive studies with more patients are needed. As vitamin D deficiency observed in healthy individuals makes us think that it is a common condition throughout the society, the causes of vitamin D deficiency should be investigated, these reasons should be eliminated by making more extensive studies, and vitamin D supplementation should be made if necessary. Thus, we think that illnesses which belong to vitamin D deficiency can be prevented

\section{Acknowledgement}

We thanks to our Hospital for this research.

\section{References}

1. Sevim S. Multipl Skleroz Atakları ÜzerineGüncelleme: Tanım, Patofizyoloji, Özellikler. Taklitçiler ve Tedavi Turk J Neurol; 2016.22:99-108. DOI: $10.4274 /$ tnd. 75318

2. Wekerle H. Nature plus Nurture: The triggering of multiple sclerosis. Swiss Med Wkly; 2015.145:w14189. DOI: 10.4414/smw.2015.14189

3. Sintzel MB, Rametta M, Reder AT. Vitamin D and Multiple Sclerosis: A Comprehensive Review. Neurol Ther; 2018. Jun;7(1):59-85. DOI :10.1007/s40120-0170086-4

4. Smolders J, Moen SM, Damoiseaux J, Huitinga I, Holmøy $\mathrm{T}$ Vitamin $\mathrm{D}$ in the healthy and inflamed central nervous system: Access and function. Neurol Sci; 2011. Dec;15.31(1-2):37-43. DOI: 10.1016/j.jns.2011.07.033

5. Nikanfar M, Taheri-Aghdam AA, at al. Serum $25(\mathrm{OH})$ Vitamin D levels is not associated with disability in multiple sclerosis patients: A case-control study. Iran J Neurol; 2015.

PIMCID:PMC4395802

6. Goral A, Brole V, Kaspryzk M, Przybylski W. The role of vitamin D in the pathogenesis and course of multiple sclerosis Wiad Lek; 2015.68(1):60-6. PMID26094335

7. Sospedra M, Martin R. Immunology of multiple sclerosis. Annu Rev Immunol; 2005.23:683-747. DOI: 10.1146/annurev.immunol.23.021704.115707

8. Chun RF, Liu PT, Modlin RL, et al. Impact of vitamin $\mathrm{D}$ on immune function: Lessons learned from genomewide analysis. Front Physiol; 2014.5:151. DOI: 10.3389/fphys.2014.00151.

9. Deluca, G. C., S. M. Kimball, J. Kolasinski, S. V. Ramagopalan, and G. C. Ebers. 2013. Review: The role of vitamin $\mathrm{D}$ in nervous system health and disease. Neuropathology and applied neurobiology; 39:458-484. doi: 10.1111/nan.12020.

10. Nashold, F. E., C. D. Nelson, L. M. Brown, and C. E. Hayes. One calcitriol dose transiently increases Helios+FoxP3+ T cells and ameliorates autoimmune demyelinating disease. J Neuroimmunol; 2013. Oct;15.263(1-2):64-74.

DOI: 10.1016/j.jneuroim.2013.07.016.

11. Holick MF, Cook S, Suarez G and Rametta M. Vitamin D Deficiency and Possible Role in Multiple Sclerosis. European Neurological Review; 2015.10(2):131-8

12. Nashold, F. E., C. D. Nelson, L. M. Brown, and C. E. Hayes. One calcitriol dose transiently increases Helios+FoxP3+Tcells and ameliorates autoimmune demyelinating disease. J Neuroimmunol; 2013.263.6474. DOI: 10.1016/j.jneuroim.2013.07.016.

13. Hayes CE, Nashold FE, Mayne CG, at all. Vitamin D and multiple sclerosis. Elsevier; 2011.1843-1877. DOI: 10.1016/B978-0-12-381978-9.10095-2.

14. Munger KL1, Levin LI, Hollis BW, Howard NS, Ascherio A. Serum 25- hydroxyvitamin D levels and risk of multiple sclerosis. JAMA; 2006. Dec;20.296(23):2832-8. DOI: 10.1001/jama.296.23.2832.

15. Burton JM, Kimball S, Vieth R at al. A phase I/II doseescalation trial of vitamin D3 and calcium in multiple 
sclerosis. Neurology; 2010. Jun;8.74(23):1852-9. DOI: 10.1212/WNL.0b013e3181e1cec2.

16. Mowry EM1, Waubant E, McCulloch CE at al. Vitamin $\mathrm{D}$ status predicts new brain magnetic resonance imaging activity in multiple sclerosis. Ann Neurol; 2012 Aug.72(2):234-40. DOI: 10.1002/ana.23591.

17. Mokry LE, Ross S, Ahmad OS, et al. Vitamin D and Risk of Multiple Sclerosis: A Mendelian Randomization Study. PLoS Med; 2015. Aug;25.12(8):e1001866. DOI: 10.1371/journal.pmed.1001866.

18. Van der Mei IA, Ponsonby AL, Dwyer T et al. Vitamin $\mathrm{D}$ levels in people with multiple sclerosis and community controls in Tasmania, Australia. J Neurol. 2007 May;254(5):581-90. Epub 2007 Apr 11. DOI:10.1007/s00415-006-0315-8

19. Marjan A, Mahtab R, Neda Z et al Serum Vitamin D Level in Iranian Multiple Sclerosis patients and their Siblings: A Case-Control Study .J Neurol Stroke; 2017.6(1): 00190. DOI:10.15406

20. Soilu-Hanninen M, Aivo J, Lindstrom BM, et al. A randomised, double blind, placebo controlled trial with vitamin D3 as an add on treatment to interferon beta-1b in patients with multiple sclerosis. J Neurol Neurosurg Psychiatry; 2012. May;83(5):565-71. DOI: 10.1136/jnnp-2011-301876.

21. Derakhshandi H1, Etemadifar M, Feizi A,et al. Preventive effect of vitamin D3 supplementation on conversion of optic neuritis to clinically definite multiple sclerosis: a double blind, randomized, placebocontrolled pilot clinical trial. Acta Neurol Belg; 2013. Sep;113(3):257-63. DOI: 10.1007/s13760-012-0166-2.
22. Smolders J, Menheere P, Kessels A at al .Association of vitamin D metabolite levels with relapse rate and disability in multiple sclerosis. Mult Scler; 2008 Nov;14(9):1220-4. DOI: 10.1177/1352458508094399.

23. Chaudhuri JR, Mridula KR, Umamahesh M, et al. Association of Serum 25-hydroxyvitamin D in Multiple Sclerosis: A Study from South India Remedy Publications LLC. Neurological Disorders and Stroke International; 2018. Volume 1 Issue 2 Article 1006.

24. Kimball SM1, Ursell MR, O'Connor P, Vieth R Safety of vitamin D3 in adults with multiple sclerosis. Am J Clin Nutr; 2007. Sep;86(3):645-51. DOI: 10.1093/ajen/86.3.645.

25. Pihl-Jensen G, Frederiksen JL. 25-Hydroxyvitamin D levels in acute monosymptomatic optic neuritis: Relation to clinical severity, paraclinical findings and risk of multiple sclerosis.. J Neurol; 2015. Jul;262(7):1646-54. DOI: 10.1007/s00415-015-7740-5.

26. Darwish H, Haddad R, Osman S, at al of Vitamin D Replacement on Cognition in Multiple Sclerosis Patients. Sci Rep; 2017. Apr;4.7:45926. DOI: 10.1038/srep45926

27. Laursen JH, Søndergaard HB, Sørensen PS, et al. Vitamin D supplementation reduces relapse rate in relapsing-remitting multiple sclerosis patients treated with natalizumab. Mult Scler Relat Disord; 2016. Nov;10:169-173. DOI: 10.1016/j.msard.2016.10.005.

28. Ascherio A1, Munger KL1, White R2, et al. Vitamin D as an early predictor of multiple sclerosis activity and progression. JAMA Neurol; 2014. Mar;71(3):306-14. DOI: 10.1001/jamaneurol.2013.5993. 